\title{
Peranan Perempuan Menurut Perjanjian Baru bagi Perkembangan Kepemimpinan Perempuan di dalam Gereja
}

\author{
Nunuk Rinukti Siahaya \\ Sekolah Tinggi Agama Kristen Teruna Bhakti, Yogyakarta \\ nunuksiahaya@gmail.com
}

\begin{abstract}
A woman is more often become second-class citizens in terms of leadership. Although age has become the time of emancipation, however, in some sectors of life, a women have not got the right place and in accordance with nature. This also happens in church life. Many of the rules and procedures that the church does not provide flexibility for women to lead. There are many reasons, such as reasons for prohibiting the biblical text, up to a certain cultural reasons, including certain church culture that has not provided the opportunity for women to lead. Therefore, in this Tulsan authors highlight the role of women in the New Testament for the development of women's leadership in the church.
\end{abstract}

Keywords: Bible, church, leadership, New Testament, women

\begin{abstract}
Abstrak: Perempuan atau wanita lebih sering menjadi warga kelas dua dalam hal kepemimpinan. Walaupun zaman ini telah menjadi zaman emansipasi, namun demikian di beberapa sector kehidupan, perempuan atau wanita belum mendapat tempat yang pas dan sesuai dengan kodratnya. Hal ini juga terjadi di dalam kehidupan bergereja. Banyak peraturan dan tata gereja yang tidak memberikan keleluasan bagi perempuan untuk memimpin. Ada banyak alas an, seperti alas an teks Alkitab yang melarang, sampai alas an budaya tertentu, termasuk budaya gereja tertentu yang belum memberikan kesempatan kepada perempuan untuk memimpin. Oleh karena itu, dalam Tulsan ini penulis menyoroti peranan perempuan dalam Perjanjian Baru demi perkembangan kepemimpinan perempuan di dalam gereja.
\end{abstract}

Kata kunci: Alkitab, gereja, Perempuan, Perjanjian Baru, kepemimpinan

\section{Pendahuluan}

R.A. Kartini, merupakan seorang pembawa pembaharuan wanita di dalam masyarakat Indonesia, khususnya dengan gerakan emansipasi wanita. Jauh sebelumnya, dalam konteks umat Tuhan dalam Alkitab, telah muncul para wanita yang sangat berpengaruh dan bahkan mampu mempengaruhi dan mengubah sejarah, khususnya sejarah perjalanan umat Tuhan. Misalnya Miryam, yang mempunyai peran yang sangat signifikan dalam proses perjalanan umat Tuhan ke Tanah Perjanjian. Rahab, Rut, Debora dan Ester di dalam konteks Perjanjian Lama, mempunyai peran yang sangat besar dalam sejarah umat Tuhan.

Di dalam Perjanjian Baru, ditemukan beberapa wanita yang secara tersurat maupun tersirat berperan dengan baik dalam melayani maupun membantu pelayanan para pelayan Tuhan pada saat itu. Maria, Elisabet, Lidia, Priskila, Febe, merupakan wanita-wanita yang mengambil peran tersebut. Namun demikian, semuanya menjadi kotradiksi, apabila bacaan 
yang terdapat di dalam I Timotius 2:11-15, menjadi acuan bagi peran serta perempuan dalam kepemimpinan di dalam Gereja. Itulah sebabnya tulisan ini dibuat untuk memberikan pemahaman yang benar tentang bagian ini.

Tulisan ini berjudul "Peranan Perempuan menurut Perjanjian Baru bagi Perkembangan Kepemimpinan Perempuan di dalam Gereja." Yang dapat dijabarkan sebagai berikut: Pertama adalah peran. Peran artinya ikut ambil bagian dalam suatu kegiatan dan dilakukan secara aktif. ${ }^{1}$ Kedua adalah Perempuan, yang adalah jenis dari manusia yang berlawanan dengan laki-laki. ${ }^{2}$ Ketiga adalah implementasi. Implementasi berarti melaksanakan apa yang telah disepakati secara bersama. ${ }^{3}$ Keempat, kepemimpinan. Kata "kepemimpinan" mengalami berbagai ragam definisi yang dibuat oleh para pakar yang telah berpengalaman dalam hal kepemimpinan itu sendiri. Yakob Tomatala mengartikan kepemimpinan sebagai istilah yang sofistikatif. ${ }^{4}$ Istilah dipakai untuk menjelaskan pengaruh-pengaruh politik, ekonomi, dan sebagainya, khususnya yang berkaitan dengan manajemen, pengontrolan mutu dan efektifitas, serta efisiensi kerja. ${ }^{5}$

Dilain pihak Ted Engstrom dan Edward Dayton memberikan definisi kepemimpinan dengan beberapa kata saja. Menurut mereka, definisi yang paling tepat untuk kepemimpinan adalah seseorang yang mempunyai pengikut-pengikut dalam situasi tertentu. ${ }^{6}$ Selanjutnya dikatakan bahwa tidak semua orang akan menjadi pemimpin. Seorang pemimpin akan dikenali dari realita bahwa ia mempunyai pengikut. ${ }^{7}$ Definisi dan pengertian yang lebih sederhana lagi dibuat oleh Hans Finzel. Menurutnya kepemimpinan adalah sebuah pengaruh. Artinya jika seseorang dapat mempengaruhi orang lain untuk melakukan sesuatu, itu berarti ia telah memimpin orang tersebut. ${ }^{8}$

George Barna mengutip pernyataan Warren Bennis dan Burt Nanus, mengatakan bahwa; "Kepemimpinan adalah melakukan segala sesuatu dengan benar". 9 Selanjutnya Barna juga mengutip tulisan Vance Packard yang mengatakan: "Kepemimpinan adalah membuat orang lain ingin melakukan sesuatu yang aku yakini harus dilakukan."10

\section{Persoalan Pemimpin Perempuan dalam Gereja}

Dalam konteks gereja Tuhan, sudah banyak perempuan yang menjadi pemimpin dan gembala sidang di gereja-gereja lokal. Selain itu, perempuan-perempuan mendapat tempat yang cukup layak untuk mengajar dan menjadi orang yang cukup berperan dalam kehidupan masyarakat. Persoalan yang muncul dalam penulisan ini adalah bermula dari

\footnotetext{
${ }^{1}$ Kamus Besar Bahasa Indonesia. (Jakarta: Balai Pustaka, 2005), 855

${ }^{2}$ W.J.S. Purwodarminta., Kamus Umum Bahasa Indonesia (Jakarta: Balai Pustaka, 1983), 738

${ }^{3}$ Kamus Besar. 427

${ }^{4}$ Yakob Tomatala, Kepemimpinan yang Dinamis (Jakarta: YT Leadership Foundation, 1997), 9.

${ }^{5}$ Ibid.

${ }^{6}$ Ted W. Engstrom dan Edward R. Dayton, Seni Manajemen Pemimpin Kristen (Bandung: Kalam Hidup, 1998), 18.

${ }^{7}$ Ibid.

${ }^{8}$ Hans Finzel, Sepuluh Besar Kesalahan yang dibuat Para Pemimpin (Batam: Interaksara, 2002), 13.

${ }^{9}$ George Barna, Leaders On Leadership (Malang: Gandum Mas, 2002), 22.

${ }^{10}$ Ibid. 23.
} 
pertanyaan "apakah perempuan diijinkan oleh Alkitab untuk berkiprah dalam kepemimpinan?" Hal ini perlu diangkat, mengingat bahwa Alkitab sebagai dasar atau pegangan hidup orang Kristen, dalam hal ini perempuan Kristen, tidak keliru dan bertentangan dengan firman Tuhan.

Hal pertama yang menjadi permasalahan dalam tulisan ini adalah: Ada beberapa perempuan yang menjadi pemimpin dalam jemaat atau gembala sidang, seakan-akan menjadi begitu dominan, kadangkala sampai terbawa ke dalam kepemiminan di rumah tangga. Glenda Malmin dalam bukunya mengatakan:

Peran seorang wanita Kristen haruslah sesuai dengan panggilannya sebagai wanita. Apabila wanita melupakan kodratnya sebagai seorang "pendaping" yang sepadan bagi suaminya, maka wanita tersebut telah mengingkari tidak hanya kodratnya, tetapi juga panggilannya sebagai seorang pendamping yang setia bagi suaminya. ${ }^{11}$

Jadi, seorang perempuan dapat berperan sebagai seorang pemimpin dan itu tidak bertentangan dengan kehendak Allah. Namun demikian, perananan sebagai seorang wanita sesui dengan kodratnya dan penggilannya sebagai seorang pendamping yang sepadan bagi suaminya harus juga dijalankan sesuai dengan rencana dan kehendak Tuhan.

Kedua, walaupun perempuan sudah mendapat tempat yang layak dalam aktualisasi hidup untuk melayani, namun masih ada sedikit "diskriminasi" dimana, jarang sekali wanita atau perempuan, diberikan porsi yang tepat untuk menjadi pemimpin tertinggi gereja, seperti ketua sinode, dan sebagainya. Padahal, jika melihat keluar dari konteks gereja dan keKristenan, banyak wanita atau perempuan yang menjadi pemimpin tertinggi dari satu instansi, perusahaan, bahkan partai politik.

Barangkali tidak ada isu yang lebih diperdebatkan dalam gereja sekarang ini dibanding dengan isu mengenai perempuan yang melayani sebagai pendeta atau pengkhotbah. Karena itu sangat penting untuk tidak memandang isu ini sebagai laki-laki melawan perempuan. Ada perempuan-perempuan yang percaya bahwa perempuan tidak sepatutnya melayani sebagai Pendeta dan bahwa Alkitab membatasi pelayanan dari para perempuan, dan ada pula laki-laki yang percaya bahwa perempuan dapat melayani sebagai Pendeta dan tidak ada batasan bagi perempuan yang melayani. Ini bukan soal chauvinisme atau diskriminasi. Isu ini adalah soal penafsiran Alkitab.

Dalam I Timotius 2:11-12 mengatakan, "Seharusnyalah perempuan berdiam diri dan menerima ajaran dengan patuh. Aku tidak mengizinkan perempuan mengajar dan juga tidak mengizinkannya memerintah laki-laki; hendaklah ia berdiam diri." Dalam gereja Allah menetapkan fungsi yang berbeda pada laki-laki dan perempuan. Ini adalah karena cara umat manusia diciptakan (1 Tim. 2:13) dan cara dosa masuk ke dalam dunia (2 Tim. 2:14). Allah, melalui tulisan dari Rasul Paulus, membatasi perempuan dari pelayanan pengajaran rohani yang memberikannya otoritas atas laki-laki. Hal ini membatasi

\footnotetext{
${ }^{11}$ Glenda Malmin. Wanita engkau Dipanggil dan Diurapi. (Jakarta: Imanuel Publishing House, 2002),
} 
perempuan dari pelayanan sebagai Pendeta, yang meliputi berkhotbah, mengajar dan memiliki otoritas rohani atas laki-laki.

Pandangan terhadap pendeta perempuan dalam pelayanan yang seperti ini mendapatkan banyak "keberatan." Keberatan yang umum adalah bahwa Paulus membatasi perempuan dari mengajar karena pada abad pertama perempuan biasanya tidak berpendidikan. Namun demikian, 1 Timotius 2:11-14 sama sekali tidak menyinggung status pendidikan. Kalau pendidikan menjadi kualifikasi untuk pelayanan, mayoritas murid Yesus mungkin sekali tidak akan memenuhi syarat. Keberatan kedua yang sering diutarakan adalah bahwa Paulus hanya membatasi perempuan-perempuan Efesus dari pelayanan (1 Timotius ditulis kepada Timotius yang adalah Pendeta dari gereja di Efesus). Kota Efesus terkenal dengan kuil Artemis, seorang dewi Roma atauYunani. Dalam penyembahan kepada Artemis, perempuan adalah pemegang kekuasaan. Namun demikian, kitab I Timotius sama sekali tidak menyinggung tentang Artemis. Paulus juga tidak menyinggung penyembahan pada Artemis sebagai dalih dari larangan dalam 1 Timotius 2:11-12.

Keberatan ketiga adalah Paulus hanya merujuk pada suami dan isteri, bukan laki-laki dan perempuan secara umum. Kata-kata Bahasa Yunani dalam 1 Timotius 2:11-14 dapat merujuk pada suami dan isteri. Namun demikian, arti dasar dari kata-kata tsb. adalah lakilaki dan perempuan. Lebih lanjut lagi, kata-kata bahasa Yunani tsb juga digunakan dalam ayat 8-10. Apakah hanya suami-suami yang boleh berdoa dengan menadahkan tangan yang suci tanpa marah dan perselisihan (ayat 8)? Apakah hanya para isteri yang yang harus berpakaian dengan sopan, melakukan perbuatan baik dan beribadah kepada Allah (ayat 910)? Tentu tidak. Jelas bahwa ayat 8-10 merujuk pada laki-laki dan perempuan secara umum dan bukan hanya suami dan isteri. Tidak ada sesuatupun dalam konteksnya yang mengindikasikan adalah peralihan kepada suami dan isteri dalam ayat 11-14.

Keberatan lain yang sering diutarakan terhadap pendeta atau pengkhotbah perempuan adalah dalam hubungannya dengan Miryam, Debora, Hulda, Priskila, Phebe, dan sebagaiinya, para perempuan yang memegang posisi kepemimpinan dalam Alkitab. Keberatan ini lalai memperhatikan beberapa faktor penting. Debora adalah satu-satunya hakim perempuan di antara 13 hakim-hakim laki-laki. Hulda adalah satu-satunya nabiah yang disebutkan dalam Alkitab di antara sekian banyak nabi-nabi laki-laki. Satu-satunya koneksi Miryam kepada kepemimpinan adalah karena dia adalah saudara perempuan dari Musa dan Harun. Kedua perempuan yang paling tekenal dalam zaman Raja-Raja adalah Atalya dan Izebel dan mereka tidak dapat disebut sebagai teladan perempuan yang rohani.

Dalam kitab Kisah Para Rasul pasal 18 Priskila dan Akwila diperkenalkan sebagai hamba-hamba Kristus yang setia. Nama Priskila disebut lebih dahulu, kemungkinan besar mengindikasikan bahwa dalam pelayanan dia lebih "utama/penting" dibanding dengan suaminya. Sekalipun demikian, Priskila sama sekali tidak dikatakan berpartisipasi dalam aktifitas pelayanan yang bertolak belakang dengan I Timotius 2:11-14. Priskila dan Akwila 
membawa Apolos ke rumah mereka dan mereka berdua memuridkan dia dan menjelaskan Firman Tuhan kepada Apolos dengan lebih akurat (Kisah Rasul 18:26).

Dalam Roma 16:1, bahkan jika Phebe dianggap sebagai "diaken perempuan" dan bukan "hamba," ini tidak mengindikasikan bahwa Phebe adalah guru dalam jemaat. "Dapat mengajar" adalah salah satu persyaratan penatua dan bukan diaken (I Timotius 3:1-13; Titus 1:6-9). Penatua/penilik jemaat/diaken digambarkan sebagai "suami dari satu isteri," "disegani dan dihormati oleh anak-anaknya," dan "mempunyai nama baik." Lebih dari itu, dalam I Timotius 3:1-13 dan Titus 1:6-9, kata ganti maskulin digunakan secara eksklusif untuk menunjuk pada para penatuaatau penilik jemaat atau diaken.

Keberatan atau sanggahan-sanggahan yang berhubungan dengan peran serta keterlibatan perempuan di dalam gereja, baik dari segi sosial, budaya, maupun pengaruh beberapa teks Alkitab yang berimplikasi terhadap perempuan, membuat penulis mengangkat tulisan ini sebagai bagian untuk menyanggah tanggapan-tanggapan tersebut diatas. Sudah tentu dalam tulisan ini, sorotannya diarahkan dan berfokus kepada teks-teks yang ada dalam Injil Markus, dimana dalam Injil tersebut Yesus memberikan porsi yang cukup banyak bagi para perempuan untuk terlibat dan ikut berperan dalam pelayananNya.

Ketiga, kurangnya pemahaman yang benar tentang Alkitab sehubungan dengan adanya keterlibatan perempuan sebagai pemimpin di dalam gereja. Kecenderungan masyarakat di belahan bumi bagian Timur dalam menafsirkan sesuatu, melibatkan unsur kebudayaan dan konteks setempat. Hal ini juga mempengaruhi pembaca Alkitab, termasuk di dalamnya tokoh-tokoh gereja, yang melihat bagian-bagian teks tertentu, khususnya yang berhubungan dengan perempuan secara subjektif. Penafsiran dan pemahaman teks yang benar adalah melihat kepada konteks pada waktu si penulis itu menuliskan naskah-naskah teksnya. Sehingga untuk memberikan arti yang literal atau yang normal bagi teks tersebut, maka perlu adanya pemahaman yang benar dalam membahas teks-teks yang berhubungan dengan peran serta perempuan dalam Alkitab yang tidak bertentangan dengan kehendak Allah untuk para perempuan melayani sejajar dengan kaum laki-laki.

\section{Metodologi}

Metode yang digunakan dalam artikel ini adalah deskriptif, yaitu menggambarkan secara tematik konsep ajaran Alkitab tentang peranan perempuan; bagaimana pandangan Alkitab tentang perempuan dan keterlibatannya dalam pelayanan. Teks-teks Alkitab digunakan secara tematik untuk memahami keterlibatan perempuan dalam pelayanan.

\section{Pembahasan}

\section{Perempuan dalam Ajaran Yesus Kristus}

Dalam pengajaran umumnya, Yesus Kristus tidak pernah mengeluarkan kata-kata penghinaan atau merendahkan martabat perempuan. "Kaum Hawa" itu tidak pernah menjadi obyek lelucon olok-olok atau kritikan, dan mereka tidak pernah dianggap rendah gara-gara menjadi perempuan. Dalam kutukanNya terhadap perselingkuhan dan perceraian dalam Matius 5:27-28 dan 19:3-10, Yesus Kristus mengajarkan bahwa perempuan tidak 
boleh diperlakukan sebagai obyek sex para lelaki. Perceraian suami-isteri dianggapNya sebagai bentuk dari kedegilan hati kaum Israel, sehingga memberi surat talak secara semena-mena menjadi hal yang sudah lazim. Sebab menurut Talmud, para rabbi Yahudi menafsirkan hukum Musa di luar batas. Dengan mudahnya seorang perempuan dapat diceraikan kalau ia "menyajikan makanan yang basi", bila ia berbicara keras-keras sampai didengar tetangganya atau bila suaminya telah menemukan seorang perempuan yang lebih cantik dari isterinya sendiri. $^{12}$

Dalam khotbah-khotbah-Nya, Yesus setidaknya dua kali memakai figur seorang perempuan sebagai perumpamaan untuk mengkritik ketidaksetiaan orang Israel di jaman itu, yaitu ketika diajarkanNya keteladanan janda Sarfat yang dermawan untuk menkritik para lelaki di kota Nazaret yang terkenal pelit (Lukas 4: 25-26). Perempuan kedua adalah Ratu Sheba yang datang dari Selatan untuk mendengarkan hikmat Raja Salomo. "Pada waktu penghakiman, ratu dari Selatan itu (ratu Sheba) akan bangkit bersama dengan orang dari angkatan ini dan ia akan menghukum mereka. Sebab ratu dari Selatan itu datang dari ujung bumi untuk mendengarkan hikmat Salomo, dan sesungguhnya yang ada di sini lebih daripada Salomo." Ratu Sheba yang bijak itu dikontraskan dengan pra ulama Yahudi dari madzab Farisi yang meskipun belajar Torah tetapi tidak mengerti dan tidak percaya kepada Hikmat Ilahi (Luk. 11:31).

Padahal, dalam literatur para rabbi Yahudi sendiri dikatakan bahwa Mesias yang mereka nantikan itu digambarkan sebagai Hokmah Elohim (Sirakh 24:3; Kebijakan Salomo 7: 25). Dalam tulisan Mar Ignatius, 'Yesus Kristus disebut sebagai "the Knowledge of God" atau Ilmu Allah. ${ }^{13}$ Yang dalam istilah rasul Yohanes disebut sebagai Logos (Yohanes 1:1, 14), yaitu sebutan untuk gelar Keilahian Yesus sebelum Ia ber-shekinah ${ }^{14}$ di bumi. Sekurang-kurangnya dua kali dalam perumpamaan-perumpamaan itu menggunakan figur seorang perempuan yang patut diteladani iman dan kesungguhan hatinya, yaitu perempuan yang gigih membela perkaranya terhadap seorang hakim yang tidak adil (Lukas 18: 2-8) dan perempuan yang mencari mata uang yang hilang (Lukas 15:8-10).

Yesus Kristus tidak pernah mengucapkan kata-kata yang eksplisit atau implisit mendukung pandangan bahwa wanita lebih rendah derajatnya dari kaum lelaki. Kaum perempuan selalu dihormati dalam ajaran Beliau dan mereka tidak pernah direndahkan -fakta ini patut diperhatikan dan diikuti oleh para pengkhotbah moderen jaman ini. Dalam gereja sekarang, perempuan acap kali dijadikan obyek olok-olok, pada hal kelakuan demikian tidak pernah dilakukan oleh Yesus sendiri.

\footnotetext{
${ }^{12}$ Verne. 19

${ }^{13}$ Jack N. Sparks, The Apostoloc Fathers, (Minnesota: Abigdon Press, 1978), 83

${ }^{14}$ Shekinah adalah istilah teknis Yudaisme yang berarti kehadiran Allah atau kemuliaan Allah yang nampak di bumi dalam wujud fisik yang bisa diindera oleh manusia. Lihat: Joseph Sievers, "Where Two or Three ...": The Rabbinic Concept of Shekinah and Matthew 18:20 dalam Eugene J. Fisher, The Jewish Roots of Christian Liturgy,( New York: Paulist Press, 1990), 47-57.
} 


\section{Perempuan dalam Pelayanan Paulus}

Pemberdayaan peranan perempuan dalam gereja biasanya menggunakan pemetaan peran dan melihat setiap kasus secara khusus atau secara relasional. Entah peran dalam keluarga sebagai sebagai seorang gadis, wanita muda, isteri dari seorang suami, ibu bagi anakanaknya, nyonya rumah dengan pramuwismanya, nenek bagi seluruh keluarga atau sebagai janda, kehidupan perempuan memiliki dinamika tersendiri. (1 Tim. 5: 1-2; Tit. 2:3-10; Ef. 5:22-32; 1 Pet. $3: 1-7)$. Di luar rumahnya, peranan perempuan antara lain sebagai tetangga di kampungnya, pekerja/wanita karir, aktifis kegiatan sosial-politik atau keagamaan. Setiap gereja mengembangkan pelayanan kepada kaum perempuan menurut peranan mereka masing-masing (1 Tes. 4: 11-12; 1 Pet. 2: 11-17).

Sebagai seorang gadis, kebutuhan untuk belajar dan mengembangkan bakat-bakat, bermain dan bergaul sangat penting. Berkembang dari tradisi Shema' dan ibadah hari Sabat. dalam Yudaisme, pendidikan agama bagi anak-anak gereja dilakukan melalui pelayanan Sekolah Minggu. Beberapa gereja menjadikan Sekolah Minggu bukan hanya untuk anak-anak, tetapi juga untuk semua kelompok umur, dengan sifat dan bentuk program kegiatan yang sesuai.

Adanya komisi remaja dan pemuda serta komisi wanita di dalam gereja memberi peluang bagi kaum perempuan Kristen untuk mengembangkan manajemen organisasi, berbagai ketrampilan (antara lain musik, olah raga dan kegiatan kewanitaan) dan berbagai aktifitas sosial dan nilai-nilai hidup kristiani. Kebanyakan wanita Kristen terlibat dalam pelayanan diakonia, untuk menyantuni para yatim piatu, fakir miskin, panti-panti jompo, orang-orang sakit dan yang di penjara dan kepedulian terhadap lingkungan hidup di pinggiran kota sampai ke pedesaan. Diyakini oleh gereja bahwa Almasih juga hadir di dalam diri kaum dhuafa, sehingga melayani mereka berarti sama dengan melayani Almasih (Mat. 24:40-46; 1 Yoh. 4:20).

Selain menggunakan pemetaan peran sosial perempuan, gereja memakai jalur pengembangan kharisma atau disebut juga talenta (disebut juga karunia-karunia rohani) bagi para warganya. Gereja yakin, sedikitnya setiap orang Kristen diberi kemampuan khusus sejak lahir sesuai dengan kedaulatan Allah sendiri, agar kemampuan itu dipakai untuk melayani sesama, untuk menyatakan kuasa Allah dan demi memuliakan nama Tuhan (1 Kor. 12: 4-6). Dikatakan, ada banyak kharisma di dalam gereja yang sedang aktif bekerja. Jenis-jenisnya antara lain disebut dalam Kitab Perjanjian Baru (Rom. 12: 3-8; 1 Kor. 12:4-11; Ef. 4:4-12 dan 1 Pet. 4:11). Berperannya macam-macam karunia itu dalam gereja diibaratkan satu tubuh dengan banyak anggota (1 Kor. 12: 12-30). Identitas peranan rohani seseorang dalam gereja terlihat melalui perwujudan dan pengembangan karuniakarunia rohani tadi. ${ }^{15}$ Sebagaimana diajarkan oleh rasul Petrus, "Layanilah seorang akan

\footnotetext{
${ }^{15}$ Harls Evan R. Siahaan, “Aktualisasi Pelayanan Karunia Di Era Digital,” EPIGRAPHE: Jurnal Teologi dan Pelayanan Kristiani 1, no. 1 (2017): 23-38, www.stttorsina.ac.id/jurnal/index.php/epigraphe.
} 
yang lain sesuai dengan karunia (kharisma) yang telah diperoleh tiap-tiap orang sebagai pengurus yang baik dari kasih karunia Allah" (1 Pet. 4: 10).

Sekarang, jalur peranan sosial perempuan Kristen makin banyak dengan mulai dibukanya beberapa crisis center untuk menolong orang-orang bermasalah: korban narkoba, perkosaan, kasus aborsi dan bunuh diri, incest, kaum homo dan lesbi, bahkan sampai soal pengusiran setan-setan. Selain itu gereja juga memberdayakan setiap segmentasi pelayanan, dari Sekolah Minggu, remaja dan pemuda, dewasa, hingga kepada pelayanan lansia yang tidak sedikit melibatkan kaum perempuan dalam pelayanannya. ${ }^{16}$ Gereja sadar bahwa melakukan semua ini karena bertujuan "memimpin tiap-tiap orang kepada kesempurnaan dalam Kristus" (Kol. 1: 28). Pemberdayaan perempuan berarti memberikan peran secara hakiki dan kapasitasnya, serta membantu perempuan untuk menjadi sempurna yang dikehendaki Allah (Mat. 5:48).

\section{Kesimpulan}

Perempuan dan laki-laki dengan nilai yang sama dengan Allah. Yesus Kristus datang dan mati untuk melayani dan menyelamatkan perempuan maupun laki-laki. Tetapi kesetaraan tidak memerlukan peran identik. Ayat yang sama yang mengatakan bahwa ahli waris perempuan sama keselamatan juga mengatakan kepada kaum pria untuk memperlakukan wanita secara berbeda daripada yang mereka lakukan laki-laki (1 Pet. 3:7). Sama seperti nilai-nilai perempuan Allah sangat, gereja seharusnya juga menghargai tinggi perempuan. Allah memberikan karunia rohani untuk kebaikan bersama, dan itu adalah melalui latihan dari karunia-karunia yang tumbuh gereja. Masing-masing anggota juga tumbuh sebagai mereka menggunakan karunia untuk melayani orang lain. Untuk membantu perempuan bertumbuh secara rohani, gereja perlu untuk membantu mereka menggunakan karunia yang diberikan Roh Kudus, untuk mendorong mereka untuk berpartisipasi dalam karya pelayanan di gereja.

\section{Referensi}

Armstrong, Philip E. dan Ed. Committee. “Evangelical Missions.” Quartely. 1967.

Barna, George. Depower of Vission. California : Regal Books.1992

Blanchard, Ken ; Bill Hybels and Phil Hodges. Leadhership by the Book. New York: Water Book Press. 1999.

Brougham, David Royal. Merencanakan Misi Lewat Gereja-Gereja Asia. Malang: Gandum Mas. t.t.

Carson, D. A. and John D. Woodbridge, Peny. God and Culture. Surabaya: Momentum. 2002.

Covey, Stephen R. Pinciple- Centerd Leadhership.London : Simon \& Schuster. 1988.

Covey, Stephen R. The 7 Habbits of Highly Effective People. Jakarta: Bina Rupa Aksara. 1997.

\footnotetext{
${ }^{16}$ Agustin Soewitomo Putri, "Dukungan Terhadap Anggota Keluarga Lansia Dalam Melayani," EPIGRAPHE: Jurnal Teologi dan Pelayanan Kristiani 1, no. 2 (2017): 73-90, www.stttorsina.ac.id/jurnal/index.php/epigraphe.
} 
Engstrom, Ted W., The Making Cristian Leader. Grand Rapids : Pyrane Books. 1976. Putri, Agustin Soewitomo. "Dukungan Terhadap Anggota Keluarga Lansia Dalam Melayani." EPIGRAPHE: Jurnal Teologi dan Pelayanan Kristiani 1, no. 2 (2017): 73-90. www.stttorsina.ac.id/jurnal/index.php/epigraphe.

Siahaan, Harls Evan R. "Aktualisasi Pelayanan Karunia Di Era Digital." EPIGRAPHE: Jurnal Teologi dan Pelayanan Kristiani 1, no. 1 (2017): 23-38. www.stttorsina.ac.id/jurnal/index.php/epigraphe. 